\title{
Um sistema complexo longe do equilíbrio \\ A complexidade nas críticas ao capitalismo de Wallerstein e Mészáros
}

\author{
Guilherme Vieira Dias \\ Instituto Federal de Educação, Ciência e \\ Tecnologia Fluminense, Brasil \\ gdias@iff.edu.br
}

\section{José Glauco Ribeiro Tostes \\ Universidade Estadual do Norte Fluminense, Brasil joseglaucotostes@hotmail.com}

\section{Resumo}

Tramas

A ciência de sistemas complexos de Ilya Prigogine, originalmente desenvolvida na área de físico-química para a termodinâmica do não equilíbrio ou longe do equilíbrio e suas "estruturas dissipativas", foi adaptada e incorporada às críticas do caDic. 2021 pitalismo do sociólogo estadunidense Immanuel Wallerstein e do filósofo húngaro István Mészáros. É possível identificar, em obras de ambos os autores a partir da década de 1980, a utilização de linguagem sistêmica que remete à complexidade prigogineana. No presente trabalho, apresenta-se de que forma Wallerstein e Mészáros exploram conceitos vindos das ciências naturais para entender o capitalismo como um sistema complexo longe do equilíbrio, principalmente no que diz respeito às crises cíclicas e à crise estrutural.

\section{Palavras-chave}

1| ciência 2| sistema 3 | complexidade 4 | capitalismo $5 \mid$ crises

\section{Cita sugerida}

Vieira Dias, Guilherme y Ribeiro Tostes, José Glauco (2021). Um sistema complexo longe do equilíbrio: a complexidade nas críticas ao capitalismo de Wallerstein e Mészáros. Tramas y Redes, (1), 87-102, 104a. DOI: 10.54871/c14c104a 
Tramas y Redes Dic. 2021 $\mathrm{N}^{\circ} 1$

ISSN en trámite

\title{
Un sistema complejo lejos del equilibrio: la complejidad en la crítica del capitalismo de Wallerstein y Mészáros
}

\begin{abstract}
Resumen
La ciencia de los sistemas complejos de Ilya Prigogine, desarollada originalmente en el campo de la físico-química para la termodinámica lejos del equilibrio y sus "estructuras disipativas", fue adaptada e incorporada a las críticas del capitalismo por el sociólogo estadounidense Immanuel Wallerstein y el filósofo húngaro István Mészáros. Es posible identificar, en las obras de ambos autores desde la década de 1980, el uso de un lenguaje sistémico que remite a la complejidad prigoginiana. Este artículo presenta cómo Wallerstein y Mészáros exploran conceptos de las ciencias naturales para entender el capitalismo como un sistema complejo alejado del equilibrio, especialmente en lo que respecta a las crisis cíclicas y a la crisis estructural.
\end{abstract}

\section{Palabras clave}

$1 \mid$ ciencia $2 \mid$ sistema $3 \mid$ complejidad $4 \mid$ capitalismo $5 \mid$ crisis

\section{A complex system far from equilibrium: the complexity in Wallerstein and Mészáros' criticism of capitalism}

\begin{abstract}
Ilya Prigogine's science of complex systems, originally developed in the field of physical chemistry for far from equilibrium thermodynamics and their "dissipative structures", was adapted and incorporated into the critiques of capitalism by the American sociologist Immanuel Wallerstein and the Hungarian philosopher István Mészáros. It is possible to identify, in works by both authors since the 1980s, the use of systemic language that refers to Prigoginian complexity. This paper presents how Wallerstein and Mészáros explore concepts from natural sciences to understand capitalism as a complex system far from equilibrium, especially with regard to cyclical and structural crises.
\end{abstract}

\section{Keywords}

1| science $2 \mid$ system $3 \mid$ complexity $4 \mid$ capitalism $5 \mid$ crises 
A ciência da complexidade de Ilya Prigogine ${ }^{1}$ (1984a; 1984b) foi elaborada originalmente para investigações e aplicações na área das ciências naturais. No entanto, desde os anos 1980, ela vem sendo apropriada por diversos autores da área das ciências sociais, sob um diversificado leque de interesses. ${ }^{2}$ Nesse sentido, destacam-se dois intelectuais respeitados mundialmente pela qualidade de suas obras que adotaram perspectivas sistêmicas apoiadas na complexidade prigogineana, a saber, o sociólogo estadunidense Immanuel Wallerstein e o filósofo húngaro István Mészáros.

Wallerstein, desde os anos 1980, utilizou centralmente a complexidade prigogineana para uma profunda crítica ao capitalismo. Mészáros utilizou, desde o final dos anos 1980, certos traços da ciência da complexidade prigogineana que podem ser reconhecidos implicitamente em sua vasta e robusta crítica ao capitalismo, ainda que, conforme será visto adiante, o autor não faça referência explícita à Prigogine (Tostes, 2007). Tanto Wallerstein quanto Mészáros convergem suas respectivas críticas para uma suposta crise estrutural do capitalismo, que já estaria em curso desde os anos 1970.

Pretende-se gerar uma síntese da apropriação da ciência da complexidade por parte de Wallerstein e Mészáros. Com maior destaque, será enfocado nesses autores a questão da crise estrutural ou sistêmica do capitalismo do último quarto do século XX e início do XXI descrita via complexidade, expondo-se alguns conceitos-chave de Prigogine tal como utilizados para descrever a "trajetória" capitalista e suas crises.

\section{Wallerstein e a complexidade: a análise dos sistemas-mundo}

Wallerstein defende um padrão comum, não obstante as especificidades de cada sistema, para cada um dos grandes e sucessivos sistemas históricos (ao menos os ocidentais). Em particular, a etapa ou processo final de "crise sistêmica", de cada sistema histórico, seguiria um mesmo padrão de complexidade prigogineano. Grande parte da obra de Wallerstein consiste em aprofundar a aplicação deste padrão ao que ele denomina de "crise sistêmica" do capitalismo, para distingui-la de todas as suas crises anteriores, apenas “conjunturais” ou “superáveis” (essencialmente o mesmo para Mészáros).

A seguir, eis uma boa síntese construída pelo próprio Wallerstein (2002, pp. 67-68), relativa ao sistema-mundo capitalista: 1) o sistema-mundo moderno é uma economia-mundo capitalista, o que significa que é governado pelo ímpeto de acumulação incessante de capital; 2) este sistema-mundo nasceu ao longo do século XVI e sua divisão internacional

\footnotetext{
${ }^{1}$ Prêmio Nobel de Química em 1977.

${ }^{2}$ Podemos citar como exemplos Pablo G. Casanova, Enrique Leff, entre outros.
} 


\footnotetext{
${ }^{3}$ Daqui em diante, todas as palavras destacadas em itálico dizem respeito a conceitos da ciência da complexidade, originalmente elaborados para ciências naturais, e que aparecem nos textos de Wallerstein e/ou Mészáros para tratar de sistemas históricos.
} e se expandiu ao longo de dois séculos, incorporando sucessivamente outras partes do mundo em sua divisão do trabalho, até a Ásia Oriental ser a ele incorporada em meados do século XIX; 3) o sistema-mundo capitalista adquiriu uma extensão verdadeiramente mundial, sendo o primeiro sistema-mundo a integrar o globo; 4) o sistema-mundo capitalista é constituído por uma economia mundial dominada por relações centro-periferia e uma estrutura política formada por Estados soberanos dentro de uma estrutura de um sistema inter-estados; 5) as contradições fundamentais do sistema capitalista se expressaram no bojo do processo sistêmico através de uma série de ritmos cíclicos, ${ }^{3}$ os quais têm servido para conter essas contradições; 6) os ritmos cíclicos resultaram em deslocamentos geográficos lentos, mas significativos, nos lócus de acumulação de capital e de poder, sem, entretanto, mudar as relações fundamentais de desigualdade no interior do sistema; 7) tais ciclos nunca foram perfeitamente simétricos; em vez disso, cada novo ciclo levou a cabo deslocamentos pequenos, mas significativos, nas direções particulares que constituíram as tendências seculares do sistema; 8) o sistema-mundo moderno, como todos os sistemas, é finito em duração e chegará ao fim quando suas tendências seculares alcançarem o ponto em que suas flutuações se tornarão suficientemente amplas e erráticas, deixando tais flutuações de poder garantir a viabilidade renovada das instituições do sistema; 9) quando este ponto for atingido, ocorrerá a bifurcação, e o sistema será substituído por outro ou vários outros através de um período caótico de transição.

Apresenta-se a seguir outros trechos de textos de Wallerstein que evidenciam o uso de conceitos da ciência da complexidade de Prigogine na sua teoria da crise estrutural do sistema-mundo capitalista.

A historical system is both systemic and historical [...] it has enduring structures that define it as a system - enduring, but not of course eternal. At the same time, the system is evolving second by second such that it is never the same at two successive points in time. [...] Another way to describe this is to say that a system has cyclical rhythms (resulting from its enduring structures as they pass through their normal fluctuations) and secular trends (vectors which have direction, resulting from the constant evolution of the structures). Because the modern-world system (like any other historical system) has both cycles and trends - cycles that restore

do trabalho original incluía grande parte da Europa e partes das Américas 
"equilibrium" and trends that move "far from equilibrium"- there must come a point when the trends create a situation in which the cyclical rhythms are no longer capable of restoring long-term (relative) equilibrium. When this happens, we may talk of a crisis, a real "crisis", meaning a turning point so decisive that the system comes to an end and is replaced by one or more alternative systems. Such a "crisis" is not a repeated (cyclical) event. It happens only once in life of any system, and signals its historical coming to an end. And it is not a quick event but a "transition", a long period lasting a few generations. (Wallerstein e Hopkins, 1996, p. 8)

Conforme o trecho citado, entende-se que a ampliação descontrolada de flutuações internas, geradas e enfrentadas pelo capitalismo, se dá quando esse sistema é levado, pelo acúmulo de suas próprias contradições, para longe do equilíbrio que até então conseguira sustentar, quando final e inevitavelmente as tendências seculares não mais serão "re-equilibráveis" pelos ritmos cíclicos do capitalismo. Aqui Wallerstein lança mão de uma metáfora geométrica, traduzindo essa evolução do sistema através de uma "trajetória" ou "curva da vida do sistema histórico". Enquanto há condições de sustentar-se dinamicamente o "equilíbrio sistêmico", tal curva é ascendente assintoticamente (isto é, seu crescimento é cada vez mais amortecido). O texto a seguir explicará que essa tendência ao desequilíbrio na "trajetória" desse sistema implicará em um processo caótico (deslanchado pela ampliação descontrolada de suas flutuações sistêmicas) que provocará abrupto e irreversível declínio daquela "trajetória" e finalmente desembocará em uma bifurcação que extinguirá - a partir daí - a própria "trajetória” do sistema-mundo capitalista e abrirá para novas possibilidades sistêmicas, cuja seleção é ainda, nesta etapa, "imprevisível”:

All systems (physical, biological and social) depend on cyclical rhythms to restore a minimum equilibrium. [...] But systems have [also] secular trends [which] always exacerbate the contradictions (which all systems contain). There comes a point when the contradictions become so acute that they lead to larger and larger fluctuations. In the language of the new science, this means the onset of chaos (which is merely the widening of the normal fluctuations in the system, with cumulative effects), which in turn leads to bifurcations, whose occurrence is certain but whose shape is inherently unpredictable. Out of this a new system order emerges. (Wallerstein, 1995, p. 27)

Há algum papel da intervenção ou escolha humana na decisão entre mais de uma nova possibilidade de ordem sistêmica (excluindo ao 
mesmo tempo a sustentação do atual sistema histórico), possibilidades essas que vão se desenhando nesse processo caótico que culmina numa bifurcação? Wallerstein resume a sua resposta à questão:

A chaotic situation is, in a seeming paradox, that which is most sensitive to deliberate human intervention. It is during periods of chaos, as opposed to periods of relative order, that human intervention [or choice] makes a significant difference. Chaotic situation is, in a seeming paradox, that which is most sensitive to deliberate human intervention. It is during periods of chaos, as opposed to periods of relative order, that human intervention [or choice] makes a significant difference. (Wallerstein, 1995, p. 44)

$\mathrm{Ou}$, de um ponto de vista inerente à matemática de sistemas não lineares, um outro texto do autor aponta que nestes pontos de bifurcação, ao contrário de períodos de relativa ordem, "insumos pequenos geram grande produto (em oposição ao tempo de desenvolvimento normal do sistema, quando grandes insumos geram pequeno produto"). (Wallerstein, 2002, p. 33).

\section{Mészáros e a complexidade: o sistema do capital}

Mészáros é um autor bem conhecido na área acadêmica marxista. $\mathrm{O}$ autor está em pleno acordo com o que Marx denominava de contradição capitaltrabalho e expõe tal e mesma contradição ora centrada no fator trabalho, ora na lei do valor (Mészáros, 2002).

O núcleo de seu pensamento crítico sobre o capitalismo - estando este englobado por Mészáros no sistema do capital - talvez resida numa grande comparação entre uma "fase I" do capitalismo, na qual a produção ainda atenderia progressiva e essencialmente às necessidades humanas e exigiria expansão planetária do círculo produção-consumo (de acordo com Marx), e uma "fase II" - desencadeada a partir da resposta do capital à crise de 1929 - da "produção destrutiva" (não prevista por Marx) caracterizada pela taxa de uso decrescente da produção via, originalmente, o complexo industrial-militar, isto é, com o Estado agora assumindo o papel de "consumidor" de tal produção militar. Trata-se da nova era da "obsolescência programada". Essa nova via "produtiva" do capitalismo teria conseguido deslocar, com relativo sucesso, a contradição central da superprodução - desencadeada pela crise de 1929 - apenas por algum tempo, durante a "Era do Ouro" que dura aproximadamente de 1945 ao final dos anos 1960.

A partir daí delinear-se-ia uma "fase III", que seria uma etapa de restrição (também não prevista por Marx, nem admitida por Wallerstein) à expansão geográfica do círculo produção-consumo, excluindo-se 
dele camadas crescentes de trabalhadores da periferia e mesmo do centro (tanto como força produtiva, como na condição de consumidor, dois aspectos indissociáveis). Isto é, a taxa de uso decrescente passa a aplicar-se também à "mercadoria força de trabalho" como meio imperioso de se continuar sustentando a auto-reprodução destrutiva do capital. Estariam assim sendo ativados, nessa “fase III", segundo a obra fundamental de Mészáros (2002), os limites absolutos do capital e o consequente desencadeamento de sua crise estrutural ou sistêmica, uma crise insolúvel do sistema do capital.

Tem-se aqui a forma - ainda simplificada - pela qual se desenvolve esse processo de crise para Mészáros que, segundo a interpretação dos autores do presente trabalho, tem a ver com a complexidade de Prigogine e, portanto, aproxima ao menos parcialmente as perspectivas de Mészáros e Wallerstein. Para Mészáros (2002, p. 797), em termos genéricos:

Uma crise estrutural afeta a totalidade de um complexo social em todas as relações com suas partes constituintes ou sub-complexos, como também a outros complexos aos quais é articulada. Diferentemente, uma crise não-estrutural afeta apenas algumas partes do complexo em questão e, assim, não importa o grau de severidade em relação às partes afetadas, não pode pôr em risco a sobrevivência contínua da estrutura global. Sendo assim, o deslocamento das contradições só é possível enquanto a crise for parcial, relativa e interiormente manejável pelo sistema, demandando apenas mudanças - mesmo que importantes - no interior - do próprio sistema [ainda] relativamente autônomo. Justamente, por isso, uma crise estrutural põe em questão a própria existência do complexo global envolvido, postulando sua transcendência e sua substituição por algum complexo alternativo [...] Por conseguinte, quanto maior a complexidade de uma estrutura fundamental e das relações entre elas e outras com as quais é articulada, mais variadas e flexíveis serão suas possibilidades objetivas de ajuste e suas chances de sobrevivência até mesmo em condições extremamente severas de crise. Em outras palavras, contradições parciais e "disfunções", ainda que severas, podem ser deslocadas e tornadas difusas - dentro dos limites últimos ou estruturais do sistema - e neutralizadas, assimiladas, anuladas pelas forças ou tendências contrárias, que podem até mesmo ser transformadas em forças que ativamente sustentam o sistema em questão. (grifos nossos)

Aí estão expostas algumas características sistêmicas centrais do pensamento de Mészáros, perfeitamente relacionáveis a ciência da complexidade de Prigogine. Em primeiro lugar, as partes de um complexo também podem possuir características sistêmicas (“sub-complexos”). Por sua vez, a “totalidade sistêmica" considerada pode, ela própria, formar parte dinâmica 
de um "super-sistema" (que congregaria essa "totalidade" e "outros complexos" articulados à ela). Em segundo lugar, na citação anterior está claramente exposta a forma de "auto-organização" de sistemas complexos, que pode também ser exibida (Prigogine e Stengers, 1984a) sob certas circunstâncias na matéria inanimada e, necessariamente, nos seres vivos. ${ }^{4}$ Em terceiro lugar, tem-se o apelo a uma metáfora de processo físico-químico de difusão de flutuações sistêmicas (flutuações essas, como em Wallerstein, trazidas para o campo social pelo rótulo de "contradições sistêmicas"). Em suma, tem-se - metaforicamente - um mecanismo prigogineano de "difusão de flutuações" como instrumento de amortecimento ou dissipação interna de certas flutuações perigosas a um sistema complexo.

Até aqui, focou-se mais em como Mészáros entende as formas de amortecimento/dissipação de contradições perigosas ao sistema complexo capitalista. Será demonstrado agora como ele entende, sistemicamente, o processo de crise estrutural do sistema do capital, onde não seria mais possível a esse próprio sistema amortecer as "contradições perigosas" que ele mesmo engendra. Inicialmente, Mészáros (2002) nos recorda que:

No curso do desenvolvimento histórico, as três dimensões fundamentais do capital - produção, consumo e circulação/distribuição/ realização - tendem a se fortalecer e a se ampliar por um longo tempo, provendo também a motivação interna para a sua reprodução dinâmica recíproca em escala cada vez mais ampliada. (p. 798)

Mas a seguir, o autor aponta para o fim deste relativo "equilíbrio" sistêmico do capital:

A crise estrutural do capital que começamos a experimentar nos anos 70 [...] significa simplesmente que a tripla dimensão interna [do texto anterior] de auto-expansão do capital exibe perturbações cada vez maiores. Ela [tal crise] não apenas tende a romper o processo normal de crescimento, mas também pressagia uma falha na sua função vital de deslocar as contradições acumuladas no sistema [...]. A situação muda radicalmente quando [...] os interesses de cada uma [daquelas três dimensões] deixam de coincidir com os das outras, até mesmo em última análise [leia-se: tal "falta de coincidência" não é mais apenas conjuntural]. A partir desse momento, as perturbações [...], ao invés de serem absorvidas/dissipadas/desconcentradas e desarmadas, tendem a ser tornar cumulativas e, portanto, estruturais,

\footnotetext{
${ }^{4}$ Note-se a metáfora - ainda biológica - da "sobrevivência sistêmica" empregada por Més-
} záros. 
trazendo com elas o perigoso bloqueio ao complexo mecanismo de deslocamento de contradições. Desse modo, aquilo com que [agora] nos confrontamos [...] é [...] potencialmente muito explosivo. Isto porque o capital jamais resolveu sequer a menor de suas contradições. Nem poderia fazê-lo, na medida em que, por sua própria natureza o capital nelas prospera (até certo ponto, com relativa segurança). Seu modo normal de lidar com contradições é intensificá-las, transferi-las para um nível mais elevado, deslocá-las para um plano diferente, suprimi-las quando possível, e quando não puderem mais ser suprimidas, exportá-las para uma esfera ou país diferente. (Mészáros, 2002, pp. 799-800; grifos e colchetes nossos)

Agora, tal como na descrição de Wallerstein, as turbulências (ou flutuações, ou perturbações) impostas ao sistema capitalista tendem a se tornar cumulativas, o que na linguagem sistêmica da ciência da complexidade significa mecanismo dinâmico não-linear de realimentação (feedback) positiva de uma pequena flutuação inicial no sistema.

O termo "realimentação negativa" refere-se aqui a mecanismos sistêmicos que contrabalançam e superam uma relativamente pequena, para as dimensões do sistema, flutuação inicial; já a "realimentação positiva" refere-se ao processo inverso, justamente aquele em tela agora, de uma "crise estrutural". Uma pequena flutuação se amplifica descontroladamente pelo sistema e termina por gerar um processo de transição caótico, que por sua vez o leva a um ponto de bifurcação que extingue esse sistema até então vigente, conforme foi analisado anteriormente aqui nesse trabalho por meio da aplicação da ciência da complexidade à "crise estrutural" do sistema-mundo capitalista por Wallerstein. Novamente encontra-se, agora em Mészáros, uma causalidade típica de sistemas não-lineares (em "crise"): nesse mencionado processo caótico, pequenas causas (perturbações "microscópicas" no sistema) podem gerar grandes efeitos no sistema total. Em outro texto, o pensador húngaro trabalha esse mesmo processo de ruptura sistêmica por um ângulo muito semelhante ao da "curva da vida do sistema histórico" de Wallerstein, curva que cresce de forma assintótica (isto é, crescimento cada vez mais amortecido) fruto de "tendências seculares e contraditórias" do próprio sistema, com um abrupto e irreversível declínio a partir de uma (única) crise estrutural do sistema. Compare agora com o texto de Mészáros (2002):

Quanto mais mudam as próprias circunstâncias históricas, apontando na direção de uma mudança necessária das contraditórias e cada vez mais devastadoras premissas estruturais irracionais do sistema do capital, mas categoricamente os imperativos de funcionamento devem ser reforçados e mais estreitas devem ser as margens dos 

ajustes aceitáveis [...]; a margem de deslocamento das contradições do sistema se torna cada vez mais estreita. (pp. 217-219)

Finalmente, em texto original de 1989, Mészáros (1996, pp. 391393) utilizou a linguagem da complexidade de modo significativo através de uma dada específica relação complementar ("reciprocidade dialética" nas suas próprias palavras) de tendências opostas (tendência x contra-tendência): é a relação equilíbrio x colapso do equilíbrio. Mészáros distingue o inter-relacionamento "conjuntural" entre tais pares de tendências, que pode levar inclusive à alternância de dominância de uma ou outra das tendências, de seu relacionamento nos limites do desenvolvimento de capitalismo global, onde acaba se estabelecendo "em última instância" o que Marx denominava de "momento (ou tendência) dominante". No caso da relação específica de tendências "equilíbrio x colapso do equilíbrio", Mészáros conclui que naqueles "limites" do capitalismo a desorganização e o colapso do equilíbrio vem a ser a tendência fundamentalmente dominante do sistema do capital, em lugar da tendência complementar do equilíbrio.

Note-se aqui mais uma das semelhanças de Mészáros com texto de Wallerstein, quando esse último autor tratou de "tendências seculares" e intrinsecamente contraditórias de longo prazo (e, em última instância, dominantes) do capitalismo, tendências dominantes essas que terminariam inexoravelmente por arrastar a "trajetória" do sistema histórico "para longe do seu equilíbrio" e, assim, para condições "caóticas" de "crise estrutural" (Wallerstein e Hopkins, 1996, p. 8).

\section{Fundamentos ocidental-modernos da articulação entre a crítica do capitalismo de Wallerstein e de Mészáros e a ciência da complexidade de Prigogine: relações com questões socioambientais}

O primeiro fundamento teórico, emergindo da modernidade ocidental, tem a ver com a relação "universal-particular" e corresponde ao projeto, talvez fundamental, da segunda geração do Idealismo Alemão (devidamente apropriado pelo "lado alemão" de Marx): rearticular a razão (lógica; necessidade; universal) e a história (tempo; contingência; acaso; particular), separadas - para falar de forma simplificada - por Platão e Aristóteles.

Tanto em Wallerstein quanto em Mészáros, a trajetória do sistema-mundo capitalista (ou do sistema do capital) é marcada desde seu início por contradições internas estruturais (é a parte da lógica sistêmica do capital: o "constituinte" universal da sua trajetória), nunca elimináveis pelo próprio 
sistema, ${ }^{5}$ e que geram crises históricas sucessivas, ${ }^{6}$ que vão sendo dissipadas/ deslocadas/difundidas - nunca plenamente resolvidas - e que posterior e paulatinamente ampliam inexoravelmente as barreiras ao processo acumulativo central de capital, processo sistêmico de auto-reprodução, levando tal sistema para cada vez mais longe do seu saudável e saudoso equilíbrio original. Na linguagem (complexa, avant la lettre) do próprio Marx, tal como acentuado por Mészáros (2002), no par estrutural (sistêmico) dialético de momentos equilíbrio/desequilíbrio, a tendência dominante ao fim da trajetória do sistema do capital será a do desequilíbrio.

$\mathrm{Na}$ linguagem da ciência da complexidade, as crises cíclicas, sempre ligadas às contradições estruturais do sistema, nascem como pequenas flutuações ameaçadoras à estabilidade do sistema ao longo de sua trajetória, mas sempre passíveis de "regressão" por dissipação/deslocamento/ difusão/exportação ("realimentação negativa" de pequenas flutuações) antes que se expandam incontrolavelmente e afetem o sistema como um todo ("realimentação positiva de flutuações"). Mas esse contínuo processo de dissipação de crises cíclicas, sempre benéficas inicialmente ao sistema, produz - tanto para Wallerstein, como para Mészáros e, afinal, para um Marx sistêmico - adiante barreiras cada vez maiores à rota acumulativa central do capital, acentuando suas contradições centrais. Até que pequenas flutuações não mais terão mecanismos seguros de dissipação (não há mais para onde deslocar as crises cíclicas) e aí inexoravelmente acende-se uma (única) crise estrutural ou terminal desse sistema em tela: todas as válvulas de escape para sustentar-se a acumulação de capital como que "entopem" e aquelas pequenas flutuações agora podem propagar-se, "infectando" todo o sistema e tornando-o altamente instável. Atinge-se, na linguagem prigogineana, um ponto de bifurcação onde acaba a trajetória sistêmica capitalista até então em curso e abrem-se múltiplas possibilidades (em processo não determinista) de sucessivas bifurcações (na interpretação de Wallerstein) até a emergência de um novo sistema-mundo (que Wallerstein considera impossível precisar durante a crise terminal do sistema moribundo) ou de apenas uma grande bifurcação: socialismo ou barbárie (Mészáros), isto é, ou um novo sistema-mundo (socialista) ou o caos da barbárie.

Em síntese, tem-se aqui uma apropriação marxista da ciência da complexidade prigogineana por parte de Wallerstein e Mészáros, isto é, a caracterização de uma trajetória (quase) determinista do sistema-mundo

\footnotetext{
${ }^{5}$ Pois emergem das tendências seculares - conceito de Wallerstein - sistêmicas cumulativas/ permanentes do capital.

${ }^{6}$ Crises econômicas cíclicas e conflitos sucessivos entre potências por hegemonia política no processo de acumulação de capital: ambos os processos caracterizam os "ritmos cíclicos" de Wallerstein que constituem a trama histórica, sempre contingente, daquele sistema-mundo.
} 

capitalista ou do sistema do capital (é o lado dominante da "razão" via elementos "permanentes" daquele sistema histórico), intercalada - face a emergência de nova trajetória de um futuro sistema-mundo - por instabilidades incontroláveis/ponto de bifurcação final com características não deterministas (é a "história", com sua face do acaso, do imprevisível, do "caótico", numa escala de "ciclos de civilização").

Para Wallerstein e Mészáros ter-se-ia instalado (ainda que por razões distintas), desde o início dos anos 1970, a crise terminal do sistema do capital (Mészáros) ou do sistema-mundo capitalista (Wallerstein). Ou seja, as tendências seculares mortais que perpassam toda a trajetória desse sistema (é a sua "lógica") finalmente estariam encontrando no nosso tempo suas condições históricas específicas de explosão (em flutuações/crises locais) e propagação (por todo o sistema) incontroláveis. De passagem, os autores do presente trabalho concordam que a trajetória "prigogineana" do sistema-mundo capitalista ou do sistema do capital vai levá-lo inexoravelmente a uma crise terminal (ponto de bifurcação); mas não corroboram com a tese de que essa crise iniciada na década de 1970 seja necessariamente a crise terminal. Poderá não ser: entende-se aqui que ainda existem "válvulas de escape" possíveis (incluindo, de modo original, ingredientes ambientais) para tal crise que se avoluma há cinquenta anos.

O segundo fundamento é a (re)articulação do pensamento da modernidade ocidental: rearticulação sociedade-natureza (SN) e o seu correspondente patamar epistemológico: rearticulação ciências sociais-ciências naturais, processo em curso no pensamento ocidental - de um modo mais substantivo a partir de meados do século XX - e ainda longe de sua conclusão.

Antes do alvorecer da modernidade ocidental, sociedade (S) e natureza $(\mathrm{N})$ estavam, em geral, organicamente articuladas em qualquer civilização do planeta, essencialmente via religiões e, mais particularmente no ocidente, pela via da razão aristotélica que encarava a natureza - tanto quanto a humanidade - como perpassada por "causais finais" (teleologia).

A modernidade ocidental teve na separação ou (des)articulação cartesiana entre $\mathrm{SN}$ - processo que se inaugura no início do século XVII - um dos seus aspectos mais expressivos, que se perpetua, inclusive, na academia através da face epistemológica daquela separação, a saber, a separação consequente entre ciências sociais e ciências naturais. O nascente conceito de natureza no século XVII como um "ser" neutro, objetivo, desprovido de qualquer projeto, destino ou "causas finais", em síntese, desprovido totalmente de "contaminações" antropomórficas (Monod, 1977), tornou-se a matriz (supostamente) ontológica das "ciências naturais".

A história da moderna relação $\mathrm{SN}$, especialmente nos últimos duzentos anos, está profundamente articulada à trajetória do sistema-mundo 
capitalista. Conforme compreendido pelo próprio Marx (citado em Mészáros, 1989) em "O Capital”, o capitalismo dos primórdios da revolução industrial precisava sustentar - "astuciosamente", segundo Marx - aquela separação SN e a (epistemologicamente) correspondente "neutralidade" e consequente dessacralização da ciência: os quadros do proletariado urbano nascente provinham do campo, onde velhas e medievais tradições religiosas/místicas/antropomórficas dos camponeses referentes à natureza poderiam se tornar sérios empecilhos ao trabalho fabril de exploração ilimitada da natureza.

Pelos meados do século XIX, Marx e Engels - opondo-se ao capitalismo - buscam (re)articular sociedade e natureza através da história, ou melhor, através da articulação entre histórias natural e humana.

Já no século XX, o sistema capitalista enfrentou a partir de 1929 uma crise de proporções devastadoras. Uma das suas estratégias sistêmicas de saída acabou levando a uma (re)articulação, não esperada nem logo detectada - entre sociedade e natureza pela via da violência (Tostes, 2006).

Finalmente, e mais importante, na segunda metade do século XX, começam várias iniciativas de (re)articulação sociedade-natureza (inclusive pela via dos movimentos ambientalistas) e, epistemologicamente, de rearticulação entre ciências humanas e ciências naturais (Pinguelli Rosa, 2005; 2006). Dentre tais iniciativas epistemológicas destaca-se aqui a de Prigogine (Prigogine e Stengers, 1984a, 1984b). Partindo da Termodinâmica do não equilíbrio ou longe do equilíbrio e de suas "estruturas dissipativas", 7 que só podem existir estavelmente em sistemas abertos (isto é, trocando energia e matéria com o "ambiente"), Prigogine é levado, num ponto central de sua obra, a contrastar a relação sociedade-natureza na visão do mundo mecanicista (newtoniana) com uma visão de mundo sistêmica fundada na ciência de sistemas complexos. Esta última ciência envolve um projeto interdisciplinar por excelência, pois a separação ciências humanas-ciências naturais é a matriz ou tronco original setecentista de todas as subsequentes separações disciplinares que ainda hoje existem no cotidiano da academia.

A articulação entre as perspectivas marxistas de crítica do capitalismo de Wallerstein e de Mészáros e a ciência de sistemas complexos de Prigogine se dá dentro do processo maior em curso de rearticulação entre sociedade e natureza ou, epistemologicamente, entre ciências sociais e ciências naturais. Em outras palavras, a ciência da complexidade de Prigogine leva para dentro do universo marxista, via Wallerstein e Mészáros, uma perspectiva mais "ecológica” de análise que a perspectiva da "máquina do

7 Termo usado para distingui-las das "estruturas de equilíbrio", que podem existir estavelmente mesmo em sistemas isolados. 
mundo newtoniana”. Conjetura-se que tal processo rearticulador entre SN - sinalizando para um além da modernidade ocidental e de sua separação central SN - será, provavelmente, mais acelerado nos próximos anos devido aos crescentes problemas socioambientais.

O terceiro e último fundamento, formando um trançado com os outros dois, tem a ver com uma faceta ainda pouco explorada da história do século XX. A ciência da complexidade de Prigogine pode ser vista como a ponta avançada de um processo bem mais geral de emergência e construção de um modelo europeu alternativo de civilização, que denominaremos de "modelo cíclico de transições caóticas", em curso desde o fim da Primeira Guerra Mundial. Paralelamente, o sistema-mundo capitalista seria produto e motor da própria modernidade européia e estaria centrado em um modelo hegemônico (isto é, em um projeto de civilização) iluminista axial-progressista - e profundamente anti-ecológico - de transformar o planeta numa sociedade de mercado. Mesmo o lado "inglês" de Marx (o "marxismo científico" de Marx como "Newton da economia") e o socialismo real (e seu "capitalismo de Estado") a partir de 1917 se apropriaram essencialmente desse modelo axial-progressista.

Grosso modo, o modelo alternativo defende um análogo "biológico" para cada civilização: nascimento, crescimento e decadência e uma descontinuidade entre cada uma delas, não dando lugar a uma linha ou fio condutor contínuo articulando - progressistamente ou não - a trajetória de tais civilizações. Esse modelo começa com traços - bastante ligados à respectiva conjuntura alemã de 1918 - de extremo pessimismo na obra de Spengler (1959) e se desdobra em geral nas mesmas cores negativas no entre guerras europeu, chegando mesmo a envolver o historiador inglês Toynbee e o estrategista Sorokin nos EUA - este último adotando uma perspectiva mais "neutra" (Capra, 2006). Mas não consegue chegar, firmemente, ao status de um "projeto de civilização".

Durante a "Era de Ouro" capitalista (1945-1973), o modelo cíclico evidentemente perde espaço para o projeto do "progresso", mas retorna sob novos prismas a partir dos anos 1980, sendo apropriado e transformado em "projeto de civilização", por exemplo, pelo físico e ambientalista Capra (2006) e, mais relevante para o presente trabalho, ainda apenas na condição de modelo, pela análise dos sistemas-mundo de Wallerstein (2004), apropriação essa que em ambos os casos ocorre consciente e principalmente pelo mesmo viés prigogineano que ambos autores imprimiram a este modelo. Nestes dois autores, esse viés fica claro quando utilizam a alternância de Prigogine entre diferentes trajetórias sistêmicas bem definidas (deterministas) com períodos (bifurcações “indeterministas") de transição "caóticas" inter-sistemas. 
Mészáros tem posição diferenciada. Se, de um lado, no fim da trajetória do multi-milenar sistema do capital se tem uma única e típica bifurcação prigogineana (socialismo ou barbárie) com resultado imprevisível a rentemente - uma enorme trajetória contínua ao longo de larga parte da história das civilizações. Dado o caráter crescentemente socioambiental de uma crise do capital que já se desdobra há cerca de cinquenta anos, pode-se conjeturar que o modelo cíclico de civilização tem mais possibilidades de se firmar como um "projeto" nos próximos anos em detrimento do clássico projeto de civilização do progresso linear das "forças produtivas" via ciência/tecnologia.

Em síntese, a ciência da complexidade de Prigogine - uma ponta avançada do modelo civilizatório cíclico de transições caóticas - leva para dentro do universo marxista, via Wallerstein e Mészáros, uma perspectiva mais "ecológica" que aquela do modelo hegemônico do progresso linear-cumulativo.

\section{Referências}

Capra, Fritjof (2006). O ponto de mutação: a ciência, a sociedade e a cultura emergente. São Paulo: Cultrix.

Mészáros, István (2002). Para além do capital: rumo a uma teoria da transição. São Paulo: Boitempo.

Mészáros, István (1996). O poder da ideologia. São Paulo: Ensaio.

Mészáros, István (1989). Estado capitalista e produção destrutiva. São Paulo: Ensaio.

Monod, Jacques (1977). O acaso e a necessidade. Rio de Janeiro: Vozes.

Pinguelli Rosa, Luiz (2005). Tecnociências e humanidades. Vol. 1. São Paulo: Paz e Terra.

Pinguelli Rosa, Luiz (2006). Tecnociências e humanidades. Vol. 2. São Paulo: Paz e Terra.

Prigogine, Ilya e Stengers, Isabelle (1984a). A nova aliança: a metamorfose da ciência. Brasília: UNB.

Prigogine, Ilya e Stengers, Isabelle (1984b). Order out of chaos. New York: Bantam.

Spengler, Oswald (1959). The decline of the West. New York: Knopf.

Tostes, José Glauco Ribeiro (2007). Crise no capitalismo e ciência da complexidade. [Comunicação]. V Colóquio Internacional Marx e Engels (CEMARX). Campinas, Brasil.

Tostes, José Glauco Ribeiro (2006). Capitalismo no século XX: aspectos civilizadores e anti-civilizadores. Em Carvalho e Silva, J.A. (Ed.). 
Estresse no trabalho: machismo e papel da mulher. Niterói: Muiraquitã.

Wallerstein, Immanuel (2004). World-systems analysis: an introduction. Durham: Duke University Press.

Wallerstein, Immanuel (2002). O fim do mundo como o concebemos: ciência social para o século XXI. Rio de Janeiro: Revan.

Wallerstein, Immanuel (1995). After Liberalism. New York: The New Press.

Wallerstein, Immanuel e Hopkins, Terence (Ed.) (1996). The age of transition: trajectory of the world-system, 1945-2025. London: Zed Books. 